\title{
EVALUATION OF THE RELATIONSHIP BETWEEN THE NAO AND RAINFALL EROSIVITY IN NE SPAIN DURING THE PERIOD 1955-2006
}

\author{
Marta Angulo-Martínez, Santiago Beguería \\ Estación Experimental Aula Dei (CSIC) \\ Zaragoza, Spain \\ mangulo@eead.csic.es
}

\begin{abstract}
Rainfall erosivity is the ability of precipitation to erode soil. Microerosion processes due to the impact of raindrops on the soil - rainsplash - represent an important mechanism of detachment of soil particles, which might be removed thereafter by surface runoff. The annual and interannual patterns of rainfall erosivity are controlled by the variability of rainfall intensity. This study analyses the interannual variability of daily rainfall erosivity due to precipitation in the NE of Spain during the period 1955-2006, and its connection with the North Atlantic Oscillation (NAO). It was found that the erosive power of rainfall is stronger during the negative phase of NAO and weaker during positive NAO conditions, as are the rainfall amounts. Daily rainfall erosivity series were adjusted to a Generalized Pareto probability distribution for positive and negative NAO phases for assessing the effect of NAO on extreme events. Results showed higher values expected for a given return period in most of the area under negative NAO conditions. These findings would be useful in the implementation of soil conservation strategies.
\end{abstract}

Keywords: Rainfall Erosivity; EI; North Atlantic Oscillation; R factor; NE Spain

\section{INTRODUCTION}

The concept of rainfall erosivity refers to the ability of any rainfall event to erode soil. It links together the dynamic properties of rainfall as a consequence of rainfall generating processes and their impact on the soil surface, and involves two main mechanisms: (i) rainsplash - the detachment of soil particles due to the kinetic energy of the raindrops -, and (ii) runoff erosion - motion of soil particles by shear stress exerted by the surface runoff. Rainfall erosivity is responsible of changes in the soil properties as: crusting, disruption of aggregates, removal of nutrient-rich parcels of soil, etc. Rainfall erosivity represents one of the main mechanisms of degradation in semiarid landscapes where vegetation is scarce. Its influence depends on the characteristics of soil, topography and land use, as well as on other features of the rainfall regime (D'Odorico et al., 2001). Rainfall erosivity estimates are needed for the estimation of soil erosion amounts through space and time. In the context of climate change the effect of altered rainfall characteristics combined with other aspects as biomass and changes in the soil moisture are some major concerns of soil conservation studies.

Empirical studies have demonstrated an exponential relationship between rainfall intensity and rainfall erosivity (Brown and Foster, 1987; Coutinho and Tomás, 1995; Van Dijk et al., 2002). This relationship allows introducing some important 
characteristics of the rainfall events as: (i) the raindrop size distribution and their associated kinetic energy, and (ii) the rainfall intensity at detailed time intervals.

Among the several indices developed to estimate rainfall erosivity the most extensively used is the USLE/RUSLE $R$ factor, which is calculated from the EI30 index (Wischmeier, 1959; Wischmeier and Smith, 1978; Brown and Foster, 1987; Renard et al., 1997). At many sites worldwide the $R$ factor has been shown to be highly correlated with soil loss (Van der Knijff et al., 2000; Diodato, 2004; Shi et al., 2004; Hoyos et al., 2005; Curse et al., 2006; Onori et al., 2006; Domínguez-Romero et al., 2007).

One of the main disadvantages of the RUSLE $R$ factor is the need for high frequency - typically lower than $15 \mathrm{~min}$ or pluviograph data -, long data series. Information of this nature is rarely available with adequate spatial and temporal coverage, and daily records are usually the best available data at most locations. Attempts to estimate rainfall erosivity from daily rainfall records or storm event data have been based largely on exponential relationships (Richardson et al., 1983; Bagarello and D'Asaro, 1994; Petkovsek and Mikos, 2004; Angulo-Martínez and Beguería, 2009). Due to the high temporal and spatial variability of rainfall erosivity (Angulo-Martínez et al., 2009), accurate records based on long data series are required in order to evaluate temporal or spatial trends that may be linked with atmospheric circulation patterns.

Previous work has shown that the spatial and interannual variability of rainfall intensity can be explained by atmospheric circulation patterns (Hurrell, 1995; Jones et al., 1997; Hurrell et al., 2003). The main atmospheric circulation pattern that affects the climate of Europe is the North Atlantic Oscillation (NAO). The NAO is characterized by a north-south sea-level pressure dipolar pattern, with one of the centres located over Iceland and the other one approximately over the Azores Islands. This dipolar pattern reflects the strong contrast in meridional pressure over the North Atlantic region. The positive phase of the NAO reflects below normal heights and pressure across the high latitudes of the North Atlantic, and above-normal heights and pressure over the central North Atlantic. The NAO negative mode produces high-pressure blocking in the northeast Atlantic, and a more meridional circulation than the opposite mode (Jacobeit, 1987; Moses et al., 1987). Upper-air troughs and incursions of polar air over the Mediterranean are more frequent during negative NAO, and the Atlantic storm tracks are displaced south. All these factors are responsible of wetter conditions in the western Mediterranean (Jacobeit, 1987; Moses et al., 1987; Maheras, 1988; Kutiel et al., 1996). In contrast, the NAO positive mode is characterized by moisture transport across the North Atlantic that has a more southwest to northeast orientation and extends further into northern Europe and Scandinavia. Hence, moisture transport and rainfall are reduced over southern Europe and the Mediterranean (Hurrell, 1995; Hurrell and van Loon, 1997; Moulin et al., 1997; Marshall et al., 2001). The NAO shows a clear signal throughout the whole year, but with stronger intensity and extension during winter due to the stronger meridional gradients.

The influence of the NAO on precipitation over the Iberian Peninsula has been recognized in previous studies (Rodó et al., 1997; Esteban-Parra et al., 1998; Rodríguez-Puebla et al., 1998; Serrano et al., 1999), with a clear difference between the western (Atlantic) and eastern (Mediterranean) areas of the region. It is possible to identify a large part of central and southern Spain and southern Portugal for which the influence of the NAO is dominant. In contrast, the southeastern Mediterranean coast of Spain is dominated by more easterly Mediterranean influences.

There are no previous studies relating rainfall erosivity to atmospheric teleconnection patterns in the Iberian Peninsula. Some works have addressed the influence of the El Niño-Southern Oscillation (ENSO) on rainfall erosivity for some 
areas of United States (D'Odorico et al., 2001) and Peru (Romero et al., 2007). Since the North Atlantic Oscillation controls the interannual variability of rainfall over the region, there is a need to know in which way rainfall erosivity is related to NAO. Since rainfall erosivity is more related to single extreme precipitation events than to average events, the relationship between the NAO and rainfall erosivity is not necessarily explained by the negative correlation between the NAO and total precipitation amounts. In addition, this knowledge may help agricultural managers to take soil conservation measures to protect the soil.

The aim of this study is to assess the influence of the NAO on daily rainfall erosivity in NE Spain, during the period 1955-2006. A second objective is to identify the changes in the probability of occurrences of extreme daily erosivity events in relation with daily NAO phases.

\section{STUDY AREA AND METHODS}

\subsection{Study area}

The study area covers the northeast of Spain, encompassing an area of about $147,000 \mathrm{~km}^{2}$ that corresponds to the administrative territorial province demarks which conform the Ebro Basin. The study area is geographically complex. It encloses several mountain ranges and a main central valley, the Ebro basin. The area is limited to the north by the Cantabric Sea, the Cantabrian Range and the Pyrenees, with maximum elevations above $3000 \mathrm{~m}$ a.s.l. At the south and southwest the Iberian Range closes the Ebro valley, with maximum elevations in the range of 2000-2300 $\mathrm{m}$ a.s.l. To the east valley is closed by the Catalan Prelittoral Range, with maximum elevations of 1000-1900 m a.s.l., and then continues to the Mediterranean sea.

The climate is influenced by the Atlantic and the Mediterranean, and the effect of the relief on precipitation and temperature. The bordering mountain ranges isolate the central valley, blocking the maritime influence and resulting in a continental climate with arid conditions (Lana and Burgueño 1998, Vicente-Serrano 2005). A climatic gradient in the NW-SE direction is notable, determined by strong Atlantic influences in the north and northwest of the area during much of the year, and the influence of the Mediterranean to the east. The mountain ranges add complexity to the climate of the region. The Pyrenees extend the Atlantic Ocean influence to the east by increasing precipitation. Precipitation in inland areas is characterized by alternating wet and dry periods as a consequence of the seasonal displacement of the polar front and its associated pressure systems. Inter-annual variability in precipitation can be very high, and prolonged dry periods can be followed by torrential rainfall events that last for several days. The most extreme precipitation events have been recorded along the Mediterranean seaside (Romero et al. 1998, Llasat 2001, Peñarrocha et al. 2002).

Rainfall erosivity reproduces the characteristics of the precipitation in the study area, as revealed by station-data (Figure 1). Three different areas can be recognized, following a NW-SE gradient. The NW zone, influenced by the Atlantic, shows the highest monthly rainfall values and minimum rainfall erosivity; the highest erosivity is attained at the beginning of the summer, coinciding with late spring storms. The central zone includes the majority of the observatories, with precipitation amounts that are lower than in the NW zone (although still abundant), though erosivity is greater and shows two annual peaks, one in late spring (May-June) and a second (highest) at the end of summer (August-September). The NE zone has a typical Mediterranean rainfall 
behavior, with maxima in spring and autumn and highest erosivity in autumn. It is important to note that the spring rainfall peaks are not as erosive as those of the autumn, due to differences between these seasons in rainfall generation mechanisms. Spring rainfall events are usually frequent, but tend to have low intensity. In contrast, precipitation in autumn is usually attributable to a few very intense events.

Figure 1. Homogeneous monthly rainfall erosivity regions in NE Spain (EI index, see methods section), and precipitation associated obtained by means hierarchical cluster.

Due to its complex climatology (as a consequence of being a meteorological border region) and the contrasted relief, the Ebro Basin has a long history of social, economic and environmental damage caused by extreme rainfall events (García-Ruiz et al. 2000, Lasanta 2003, Llasat et al. 2005). The main activity is agriculture representing approximately $46 \%$ of the land use. It is extended around the Ebro valley occupying a broader area close to the Mediterranean coast (figure 2). During winter agricultural soils remain uncovered. Consequently, rainfall erosivity is the principal cause of soil erosion with no limiting factor at that time. Mountain areas represent approximately $20 \%$ of the study region.

Figure 2. Spatial surface of the cultivated soil in the NE Spain $\left(68,000 \mathrm{Km}^{2}\right)$; data: Corine Land Cover version 8/2005 (EEA, 2000).

\subsection{Daily rainfall erosivity database}

The database consisted of 156 daily rainfall series from the Spanish Meteorological Agency (AEMET) for the period 1955-2006, (figure 2). Data on cumulative precipitation were taken every day at $0600 \mathrm{LT}$. The series were obtained via a process that included reconstruction, gap filling, quality control and homogeneity testing (Vicente-Serrano et al. 2009).

Figure 3. Spatial distribution of the 156 daily rainfall observatories in the study area for the period 1955-2006.

Daily rainfall series were transformed into daily rainfall erosivity records based on an exponential relationship between the rainfall volume, $P\left(\mathrm{~mm} \mathrm{~d}^{-1}\right)$, and rainfall erosivity, EI (MJ mm ha ${ }^{-1} \mathrm{~h}^{-1} \mathrm{~d}^{-1}$; Richardson et al. (1983):

$E I=a P^{b}+\varepsilon$,

where $a$ and $b$ are empirical parameters and $\varepsilon$ is a random, normally distributed error. Parameters $a$ and $b$ are adjusted month-by-month to take account of intra-annual variations in rainfall characteristics. This leads to the more general expression:

$E I_{m}=a_{m} P^{b_{m}}+\varepsilon$ 
where $m=\{1, \ldots, 12\}$ represents the month of the year. Parameter estimation in the model is achieved by weighted least squares (WLS) regression after a logarithmic transformation of the terms in equation (2). Weights were assigned to the observations in order to reduce the excessive influence of small erosive events during parameterization, (Angulo-Martínez and Beguería, 2009).

For obtaining the values of the parameters $a$ and $b$ it is necessary to count with data on daily $E I$ and $P$. This data was provided by the automated system for hydrologic information of the Ebro basin water authority (SAIH-Ebro). This dataset consisted on 110 series of rainfall data with 15 minutes resolution, covering the period 1997-2007. Daily $E I$ values were calculated from these series following the RUSLE methodology, and were used for estimating the parameters in equation (2). Given the good spatial coverage of the dataset, spatial fields of the parameters $a$ and $b$ were obtained by spatial interpolation, and their values at the location of the AEMET observatories were recorded. These values where then used to obtain daily series of EI for the period 19552006, using the AEMET daily rainfall data.

\subsection{Atmospheric circulation events: North Atlantic Oscillation index}

Following Jones et al. (1997) a North Atlantic Oscillation index (NAOI) was calculated as the normalized difference between time series of sea level pressure recorded at two points in the southwest Iberian Peninsula (Gibraltar, $35^{\circ} \mathrm{N} 5^{\circ} \mathrm{W}$ ) and southwest Iceland (Reykjavik, $65^{\circ} \mathrm{N}, 20^{\circ} \mathrm{W}$ ). Daily sea-level pressure grids from the ds010.0 Daily Northern Hemisphere Sea Level Pressure Grids data set (University Corporation for Atmospheric Research, 1979) were used for calculating the NAOI. We selected those grid points located closest to the mentioned points.

Although the NAO influence is more intense during winter time, in the present study we considered the whole year. Positive and negative events of the NAO index were identified as those days with values of the NAO index higher than 0.5 and lower than -0.5 , respectively.

\subsection{Differences in daily rainfall erosivity between positive and negative NAO phases}

To evaluate the relationship between the phase of the NAO and rainfall erosivity we computed the relative difference $E I_{\text {dif }}$ between average daily rainfall erosivity during negative NAO days and positive NAO days in every observatory:

$$
E I_{d i f}=\left(E I_{N A O-}-E I_{N A O+}\right) / E I_{N A O+},
$$

where $E I_{N A O-}$ and $E I_{N A O+}$ are the average daily rainfall erosivity during negative and positive NAO days, respectively. Maps of $E I_{d i f}$ month by month were produce to help visualize spatial differences in the effect of NAO on rainfall erosivity.

The statistical significance of the relative differences was evaluated using the Wilcoxon-Mann-Whitney (WMW) rank test (Siegel and Castelan, 1988). The nonparametric WMW test, though less powerful than the $t$ test, was preferred due to its robustness against non-normality of the variables (Helsel and Hirsch, 1992). The daily 
rainfall erosivity data series during daily negative NAO were compared with the daily rainfall erosivity data series with the opposite NAO sign, month by month. The significance level was established at $\alpha=0.05$.

\subsection{Extreme value analysis of rainfall erosivity during positive and negative NAO phases}

Changes in the probability distributions of extreme rainfall erosivity depending on the NAO phase were analyzed using the extreme value theory (Hershfield, 1973). Peaks-over-threshold (POT) series of daily erosivity $(E I)$ were obtained for positive and negative NAO phases, selecting only the observations for which $E I$ exceeded a value corresponding to the 95th percentile of the respective series. The resulting series were fitted to a Generalized Pareto (GP) distribution by the maximum likelihood approach. GP is the limit distribution of a POT variable, provided that the POT occurrences fit a Poisson process, i.e. that they are time independent. The appropriateness of the GP distribution to model the daily erosivity POT series was checked visually by means of the L-moment ratios diagram and by a Kolmogorov-Smirnov test (Beguería, 2005; Beguería et al., 2009).

The GP distribution is described by a shape parameter $k$ and a scale parameter $\alpha$, with probability density function:

$$
f(x)=\frac{1}{\alpha}\left[1-\frac{k}{\alpha}(x-\varepsilon)\right]
$$

and distribution function:

$$
P(X \leq x)=1-\left(1-\kappa \frac{(x-\varepsilon)}{\alpha}\right)^{\frac{1}{\kappa}},
$$

where $x$ is the daily rainfall erosivity exceeding the threshold value $\varepsilon$, which acts as a location parameter. Estimates of $\alpha, \kappa$ can be obtained by maximum likelihood (Rao and Hamed, 2000). The highest expected precipitation $X_{T}$ over a period of $T$ years is obtained as:

$$
X_{T}=\varepsilon+\frac{\alpha}{\kappa}\left[1-\left(\frac{1}{\lambda T}\right)^{\kappa}\right] \text {, }
$$

where $\lambda$ is the average number of events per year.

Maps of the extreme events corresponding to return periods of 10 and 50 years were produced for positive and negative NAO phased based on the GP models fitted to the POT series. These maps were compared in order to evaluate differences in expected extreme events depending on the NAO. Though NAO mostly influences during winter season, some influence can be recognised during autumn and spring. Therefore the POT analysis was applied to the period between October and February.

\section{RESULTS}




\subsection{Differences in average daily rainfall erosivity between negative and positive NAO phases}

The results of the WMW test comparing the distributions of daily erosivity during positive and negative NAO phases yielded $92(59 \%)$ of significant series globally. Monthly results are shown in Table 1 . These differences were present almost all the year, however being especially evident from autumn to early spring (OctoberMarch). Most observatories reflected this behaviour. During summer (June-August) the influence of NAO on rainfall erosivity was almost non-existent.

The spatial distribution of the significant relative differences between the daily rainfall erosivity recorded during negative and positive NAO phases for every month are shown in Fig. 4. The NAO influence can be noted from November to April, with different spatial patterns. From June to October we found no influence of NAO in rainfall erosivity, in addition, the relative differences were not significant for most of the area during June to September.

Higher differences were found closer to the Mediterranean. The highest differences between positive and negative NAO phases occurred from November to April, though March did not show any difference, most noticeable in the Mediterranean area where rainfall erosivity under negative NAO phases was between 6 and 30 times higher to the values registered under positive NAO. November showed the highest differences, affecting almost one half of the area extending from the Mediterranean coast to the west towards the centre of the Ebro valley.

Figure 4. Relative differences in average daily rainfall erosivity during negative and positive NAO phases. White masked areas indicate no significant difference.

\subsection{Differences in extreme rainfall erosivity between negative and positive NAO phases}

The GP model provided a very good fit to the POT series of rainfall erosivity, as shown by the L-moment diagrams (Fig. 5). Independently of the sign of the NAO, the empirical L-moments of the rainfall erosivity series plotted closest to the theoretical curve of the GP distribution. The results of the Kolmogorov-Smirnov test allowed accepting the GP distribution for the data, since only in very few cases the null hypothesis that the data came from a GP distribution was rejected. This result agrees with recent studies that demonstrated the high performance of the GP distribution in fitting extreme hydrological variables using partial duration series (Hosking and Wallis, 1987; Madsen and Rosbjerg, 1997; Beguería, 2005). Here we also found that the GP distribution has a good performance in fitting daily rainfall erosivity data.

Figure 5. L-moments ratio diagram, comparing empirical L-moment ratios (L-skewness and L-kurtosis) with the ones of several widely used extreme value distributions: Generalized Extreme Value (GEV), Log-Normal (LN), Pearson III (PIII) and Pareto $(G P)$.

By adjusting the daily rainfall erosivity series for the selected months to the GP probability distribution we obtained the probability of occurrence of daily rainfall erosivity records associated with negative and positive NAO conditions. Results show 
greatest rainfall erosivity values expected under negative NAO conditions. Differences could be found between observatories. Those located inland to the south of the region did not show significant differences, however, as expected by results obtained in the precedent section. The mountainous areas and the Mediterranean coast showed a high contrast between the expected rainfall erosivity values under negative or positive conditions.

The rainfall erosivity values expected for a return period of 10 years related to negative and positive NAO conditions during winter and the respective standard error are shown in Fig. 6. Under negative NAO conditions daily rainfall erosivity values of 50 up to 385 ( \pm 8 to 22 ) $\mathrm{MJ} \mathrm{mm} \mathrm{ha/h/d} \mathrm{may} \mathrm{be} \mathrm{recorded} \mathrm{in} \mathrm{the} \mathrm{northern} \mathrm{and} \mathrm{eastern} \mathrm{half}$ of the region. The highest values are concentrated at the north-east perimeter, close to theMediterranean coast from the Ebro Delta upwards to the north and in the Central Pyrenees. Under positive NAO most of the region shows low daily rainfall erosivity values ranging between 5 and $50( \pm 0.5$ to 8$) \mathrm{MJ} \mathrm{mm} / \mathrm{ha} / \mathrm{h} / \mathrm{d}$. High erosivity values are only expected in localized areas such as the Ebro Delta and in the Central Pyrenees.

Figure 6. Spatial distribution of expected daily rainfall erosivity during winter (October to March) corresponding to a return period of 10 years under negative (a) and positive

(b) NAO phases, and their respective standard errors ( $c$ and $d$, respectively).

The results are very similar for a return period of 50 years (Fig. 7), although the spatial pattern of the very high erosivity values excludes the Pyrenees region and the highest erosivity values are thus confined to the Ebro Delta.

Figure 7. Spatial distribution of expected daily rainfall erosivity during winter (October to March) corresponding to a return period of 50 years under negative (a) and positive

(b) NAO phases, and their respective standard errors ( $c$ and $d$, respectively).

\section{DISCUSION AND CONCLUSIONS}

Rainfall erosivity bridges the gap between rainfall dynamics and its direct impact over the surface of the soil, taking into account the energy of the raindrops hitting the soil, and the runoff which will remove the disaggregated soil particles. There is an increasing interest regarding the effects of the climate dynamics, especially in a context of climate change, in the environment. However, very few studies have related the atmospheric circulation patterns to rainfall erosivity due mostly to the lack of accurate rainfall erosivity series long enough to make this analysis possible.

The NAO is responsible for most of the climatic variability in the North Atlantic, modifying direction and intensity of the westerly winds, the track of the polar depressions and the location of the anticyclones. During the negative phase cyclones move southward increasing precipitation on the westernMediterranean. On the contrary, during the positive phases, the Azores subtropical high is reinforced, leading to a drier weather in the Mediterranean region.

This study has shown that atmospheric dynamics, in this case the NAO, have influenced interannual variability of rainfall erosivity at NE of Spain for the period 1955-2006. Higher rainfall erosivity values were related to negative NAO conditions whereas the high pressures associated with positive NAO conditions resulted in lower 
rainfall erosivity values. This difference was highest towards the east of the study area (Mediterranean region), and the centre of the Ebro valley, and during the winter months (November-April). Agriculture is a major land use in this area, and during this time of the year the agricultural soils are mostly uncovered and exposed to the erosive power of the rain, intensifying the impact of the NAO on soil erosion.

Knowledge of the spatial and temporal patterns of rainfall erosivity will help deepening our understanding of the processes of soil erosion, and might prove helpful for designing soil protection measures.

\section{ACKNOWLEDGEMENTS}

We thank the Spanish Meteorological Agency (Agencia Española de Meteorología, AEMET) and the Ebro Basin Water Authority (Confederación Hidrográfica del Ebro, CHE) for providing the data used in this study. The research of M.A. was supported by a JAE-Predoc Research Grant from the Spanish National Research Council (Consejo Superior de Investigaciones Científicas; CSIC).

\section{REFERENCES}

Angulo-Martínez, M., Beguería, S., 2009. Estimating rainfall erosivity from daily precipitation records: A comparison among methods using data from the Ebro Basin (NE Spain). Journal of Hydrology, 379, 111-121.

Angulo-Martínez, M., López-Vicente, M., Vicente-Serrano, S.M., Beguería, S., 2009. Mapping rainfall erosivity at a regional scale: a comparison of interpolation methods in the Ebro Basin (NE Spain). Hydrology and Earth Systems Science, 13, 1907-1920.

Bagarello, V., D’Asaro, F., 1994. Estimating single storm erosion index. Transactions of the American Society of Agricultural Engineers, 37(3), 785-791.

Beguería, S. 2005. Uncertainties in partial duration series modelling of extremes related to the choice of the threshold value, Journal of Hydrology, 303, 215-230.

Brown, L.C., Foster, G.R., 1987. Storm erosivity using idealized intensity distributions. Transactions of the American Society of Agricultural Engineers, 30: 379-386.

Coutinho, M.A.; Tomás, P.P. 1995. Characterization of raindrop size distributions at the Vale Formoso Experimental Erosion Centre. Catena, 25. 187-197.

Curse, R., Flanagan, J., Frankenberger, B., Gelder, D., Herzmann, D., James, D., Krajenski, W., Kraszewski, M., Laflen, J., Opsomer, J., Todey, D. 2006. Daily estimates of rainfall, water runoff and soil erosion in Iowa. Journal of soil and water conservation, 61 (4): 191-199.

Diodato, N. 2004. Estimating RUSLE's rainfall factor in the parto of Italy with a Mediterranean rainfall regime. Hydrology and Earth System Sciences, 8(1): 103107

D’Odorico, P.; Yoo, J.; Over, T.M. 2001. An assessment of ENSO-Induced patterns of rainfall erosivity in the Southwestern United States. Journal of Climate, 14, 4230-4242

Domínguez-Romero, L., Ayuso Muñoz, J.L., García Marín, A.P. 2007. Annual distribution of rainfall erosivity in western Andalusia, southern Spain. Journal of soil and water conservation 62 (6): 390-401. 
EEA, 2000. CORINE land cover 2000. European Environment Agency. $<$ http://image2000.jrc.it>.

Esteban-Parra MJ, Rodrigo FS, Castro-Diez Y. 1998. Spatial and temporal patterns of precipitation in Spain for the period 1880-1992. International Journal of Climatology 18: 1557-1574.

García-Ruiz, J.M., Arnáez, J., White, S.M., Lorente, A., Beguería, S. 2000. Uncertainty assessment in the predition of extreme rainfall events: an example from the Central Spanish Pyrenees. Hydrological Processes, 14: 887-898.

Helsel, D.R., Hirsch, R.M. 1992. Statistical methods in water resources. 522pp., Elesevier, New York.

Hershfield, D. M. (1973), On the probability of extreme rainfall events, Bulletin of the American Meteorological Society, 54, 1013 - 1018.

Hosking, J. R. M., and J. R. Wallis (1987), Parameter and quantile estimation for the Generalized Pareto distribution, Technometrics, 29, 339- 349.

Hoyos, N., Waylen, P.R., Jaramillo, A. 2005. Seasonal and spatial patterns of erosivity in a tropical watershed of the Colombian Andes. Journal of Hydrology, 314: 177-191.

Hurrell, J. 1995. Decadal trends in North Atlantic Oscillation and relationship to regional temperature and precipitation. Science. 269, 676-679.

Hurrell JW, van Loon H. 1997. Decadal variations in climate associated with the North Atlantic oscillation. Climatic Change 36:301-326.

Hurrell, J., Kushnir, Y., Ottersen, G., Visbeck, M. (Eds). 2003. The North Atlantic Oscillation: climate significance and environmental impacts. Geophys. Monogr. Ser., vol 134, AGU, Washinton, D.C.

Jacobeit J. 1987. Variations of trough positions and precipitation patterns in the Mediterranean area. Journal of Climatology 7: 453-476.

Jones, P.D., Jónsson, T., Wheeler, D. 1997. Extension to the North Atlantic Oscillation using early instrumental pressure observations from Gibraltar and South-West Iceland. International Journal of Climatology, 17, 1433-1450.

Kutiel H, Maheras P, Guika S. 1996. Circulation indices over the Mediterranean and Europe and their relationship with rainfall conditions across the Mediterranean. Theoretical and Applied Climatology 54: 125-138.

Lana X, Burgueño A. 1998. Spatial and temporal characterization of annual extreme droughts in Catalonia (Northeast Spain). International Journal of Climatology 18: $93-110$.

Lasanta, T. 2003. Gestión agrícola y erosión del suelo en la cuenca del Ebro: el estado de la cuestión. Zubía, 21: 76-96.

Llasat, M.C., Barriendos, M., Barrera, A., Rigo, T. 2005. Floods in Catalonia (NE Spain) since the 14th century. In Benito, G, Ouarda, T.B.M.J., Bárdossy, A (Eds.) Palaeofloods, hystorical data \& climate variability: Applications in flood risk assessment. Journal of Hydrology, 313 (1-2): 32-47.

Madsen, H., and D. Rosbjerg (1997), The partial duration series method in regional index-flood modeling, Water Resources Research, 33, 737 - 746.

Maheras P. 1988. Changes in precipitation conditions in the western Mediterranean over the last century. Journal of Climatology, 8, 179-189.

Marshall J, Kushnir Y, Battisti D, Chang P, Czaja A, Dickson R, Hurrell J, McCartney M, Saravanan R, Visbeck M. 2001. North Atlantic climate variability: phenomena, impacts and mechanisms. International Journal of Climatology, 21, $1863-1898$. 
Martin-Vide J, Gomez L. 1999. Regionalization of peninsular Spain based on the length of dry spells. International Journal of Climatology, 19, 537-555.

Moses T, Kiladis GN, Diaz HF, Barry RG. 1987. Characteristics and frequency of reversals in mean sea level pressure in the North Atlantic sector and their relationship to long-term temperature trends. Journal of Climatology, 7, 13-30.

Moulin C, Lambert CE, Dulac F, Dayan U. 1997. Control of atmospheric export of dust from North Africa by the North Atlantic oscillation. Nature 387: 691-694.

Onori, F., De Bonis, P. Grauso, S. 2006: Soil erosion prediction at the basin scale using the revised universal soil loss equation (RUSLE) in a catchment of Sicily (southern Italy). Environmental Geology, 50: 1129-1140.

Peñarrocha, D, Estrela, MJ, Millán M. 2002. Classification of daily rainfall patterns in a Mediterranean area with extreme intensity levels: the Valencia region. International Journal of Climatology 22: 677-695.

Petkovsek, G., Mikos, M. 2004. Estimating the R factor from daily rainfall data in the sub-Mediterranean climate of southwest Slovenia. Hydrological sciences journal, 49 (5): 869-877.

Rao, A. R., and K. H. Hamed (2000), Flood Frequency Analysis, CRC Press, Boca Raton, Fla.

Renard, K.G., Foster, G.R., Weesies, G.A., McCool, D.K., Yoder, D.C., 1997. Predicting Soil Erosion by Water: A Guide to Conservation Planning with the Revised Universal Soil Loss Equation (RUSLE). Handbook \#703. US Department of Agriculture, Washington, DC.

Renard, K.G., Freimund, J.R., 1994. Using monthly precipitation data to estimate the R factor in the revised USLE. Journal of hydrology, 157 (1-4): 287-306.

Richardson, C.W., Foster, G.R., Wright, D.A., 1983. Estimation of Erosion Index from Daily Rainfall Amount. Transactions of the American Society of Agricultural Engineers, 26, 153-160.

Rodó X, Baert E, Comin FA., 1997. Variations in seasonal rainfall in southern Europe during the present century: relationships with the North Atlantic oscillation and the El Niño-Southern oscillation. Climate Dynamics 19: 275-284.

Rodriguez-Puebla C, Encinas AH, Nieto S, Garmenia J. 1998. Spatial and temporal patterns of annual precipitation variability over the Iberian Peninsula. International Journal of Climatology 18: 299-316

Romero, C.C., Baigorría, G.A., Stroosnijder, L. 2007. Changes of erosive rainfall for El Niño and La Niña years in Northern Andean highlands of Peru. Climatic Change. 85, 343-356.

Romero, R., Guijarro, J.A., Ramis, C. and Alonso, S. 1998. A 30-year (1964-1993) daily rainfall data base for the Spanish Mediterranean regions: first exploratory study. International Journal of Climatology, 18: 541-560

Shi, Z.H., Cai, C.F., Ding, S.W., Wang, T.W., Chow, T.L., 2004. Soil conservation planning at the small watershed level using RUSLE with GIS. Catena, 55: 33-48

Siegel, S., Castelan, N.J. 1988. Nonparametric statistics for the behavioral sciences. McGraw-Hill, New York.

Van der Knijff, J.M., Jones, R.J.A., Montanarella, L., 2000. Soil Erosion Risk Assessment in Italy. European Commission- European Soil Bureau. 52 pp.

Van Dijk, A.I.J.M., Bruijnzeel, L.A., Rosewell, C.J. 2002. Rainfall intensity -kinetic energy relationships: a critical literature appraisal. Journal of Hydrology, 261, 123.

Vicente-Serrano, S.M., Beguería, S., López-Moreno, J.I., García-Vera, M.A., Stepanek, P. 2009. A complete daily precipitation database for north-east Spain: 
Reconstruction, quality control and homogeneity. International Journal of Climatology, DOI: 10.1002/joc.1850

Wischmeier, W.H., 1959. A rainfall erosion index for a universal soil-loss equation. Soil Science Society of America Proceedings, 23: 246-249.

Wischmeier, W.H., Smith, D.D., 1978. Predicting rainfall erosion losses: a guide to conservation planning. USDA Handbook 537, Washington, DC. 
Table 1. Difference in daily erosivity between positive and negative NAO phases (Wilcoxon-Mann-Witney test): number and proportion of series with significant differences.

\begin{tabular}{ll}
\hline Month & Significant series \\
\hline Jan & $144(92 \%)$ \\
Feb & $136(87 \%)$ \\
Mar & $68(44 \%)$ \\
Apr & $147(94 \%)$ \\
May & $109(70 \%)$ \\
Jun & $27(17 \%)$ \\
Jul & $40(26 \%)$ \\
Aug & $36(23 \%)$ \\
Sep & $11(7 \%)$ \\
Oct & $94(60 \%)$ \\
Nov & $152(97 \%)$ \\
Dec & $145(93 \%)$ \\
\hline
\end{tabular}


Figure 1
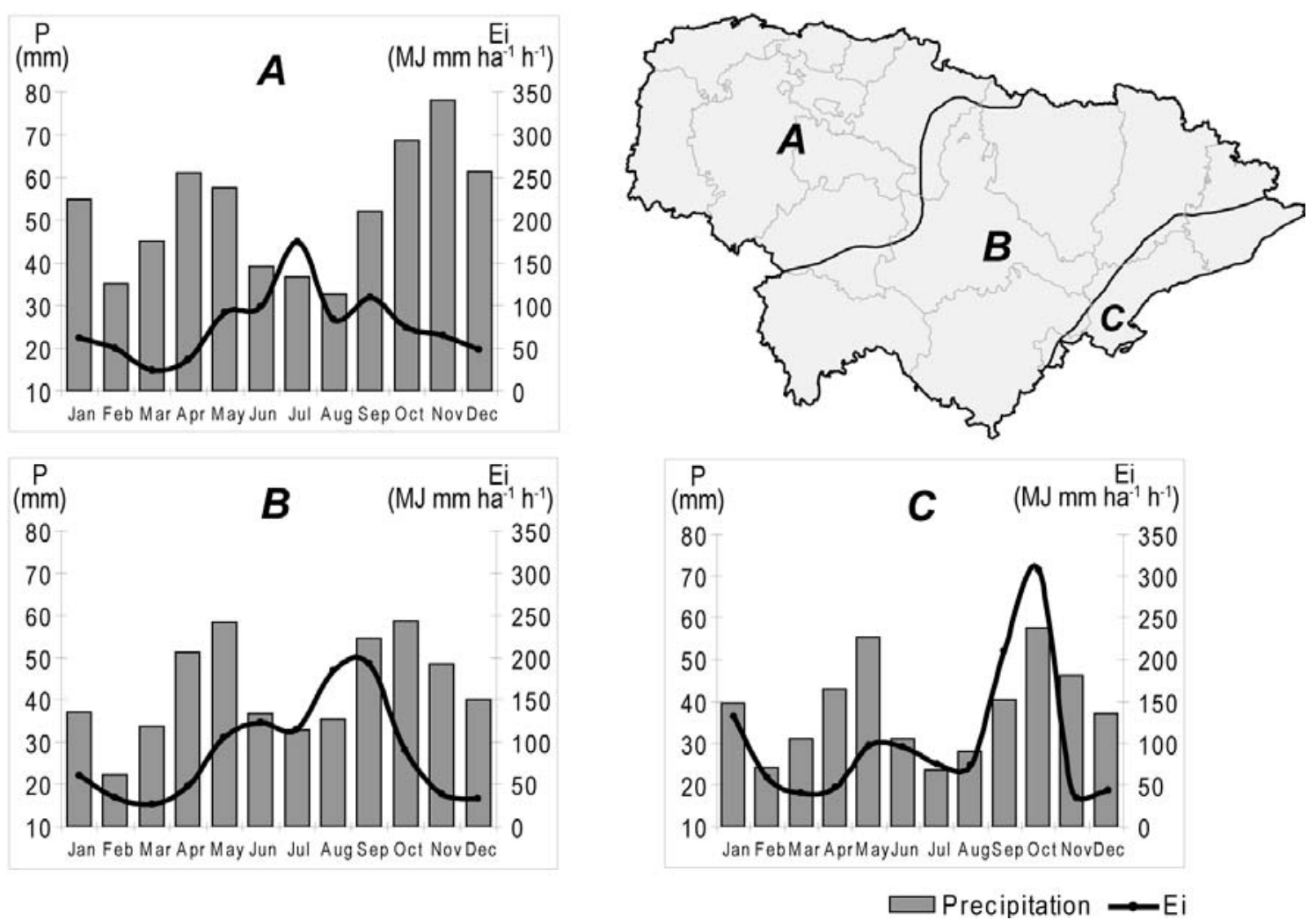


\section{Figure 2}

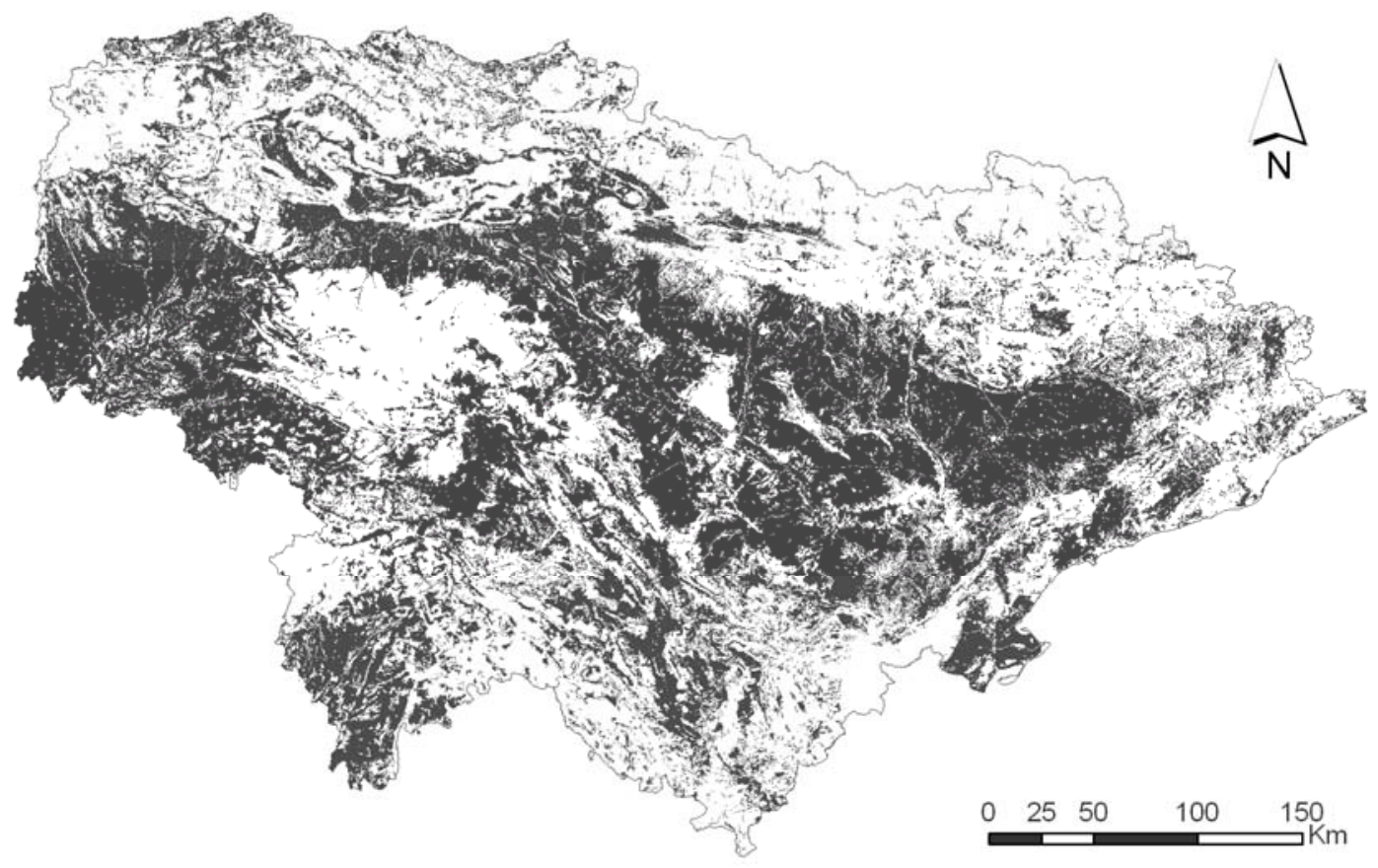


Figure 3

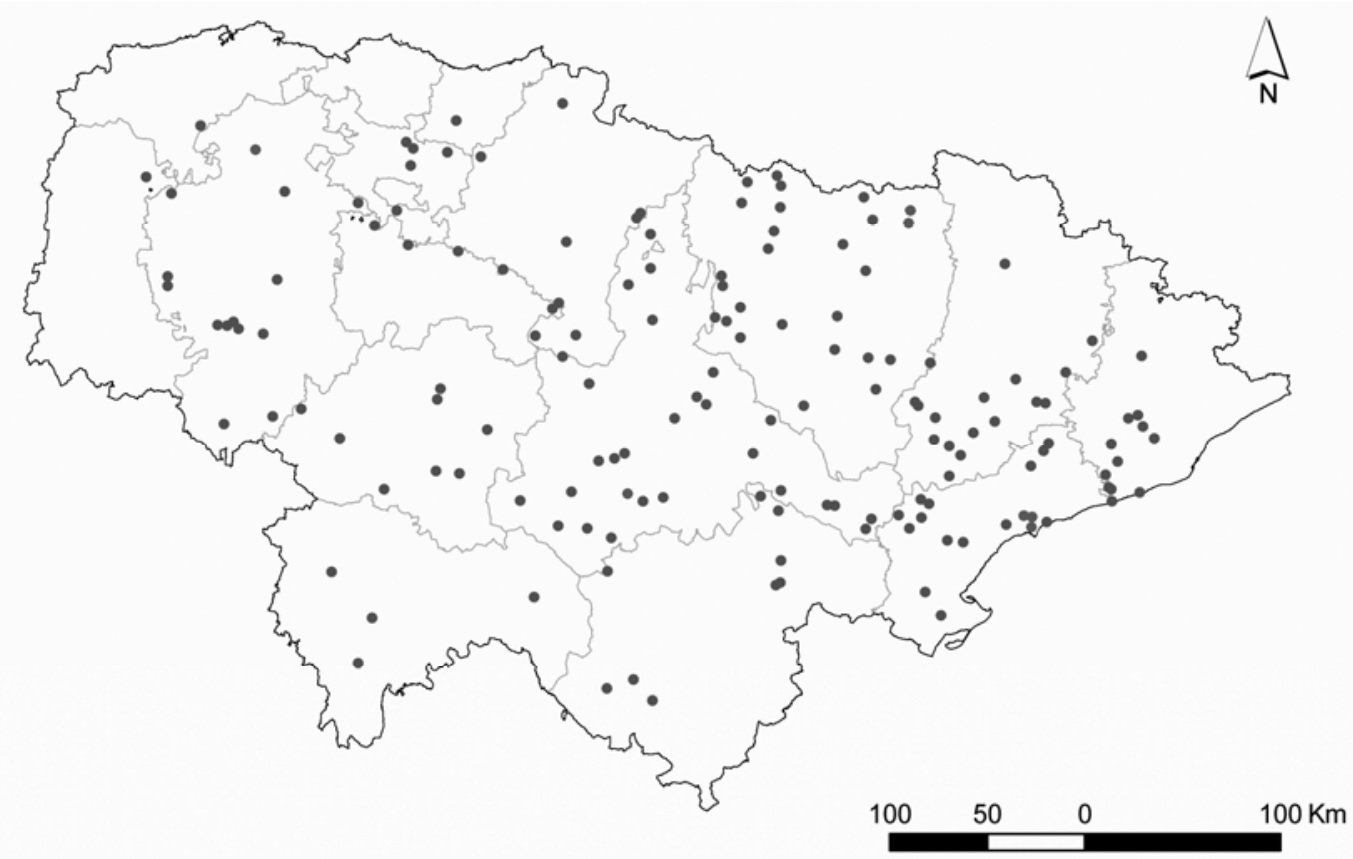


Figure 4

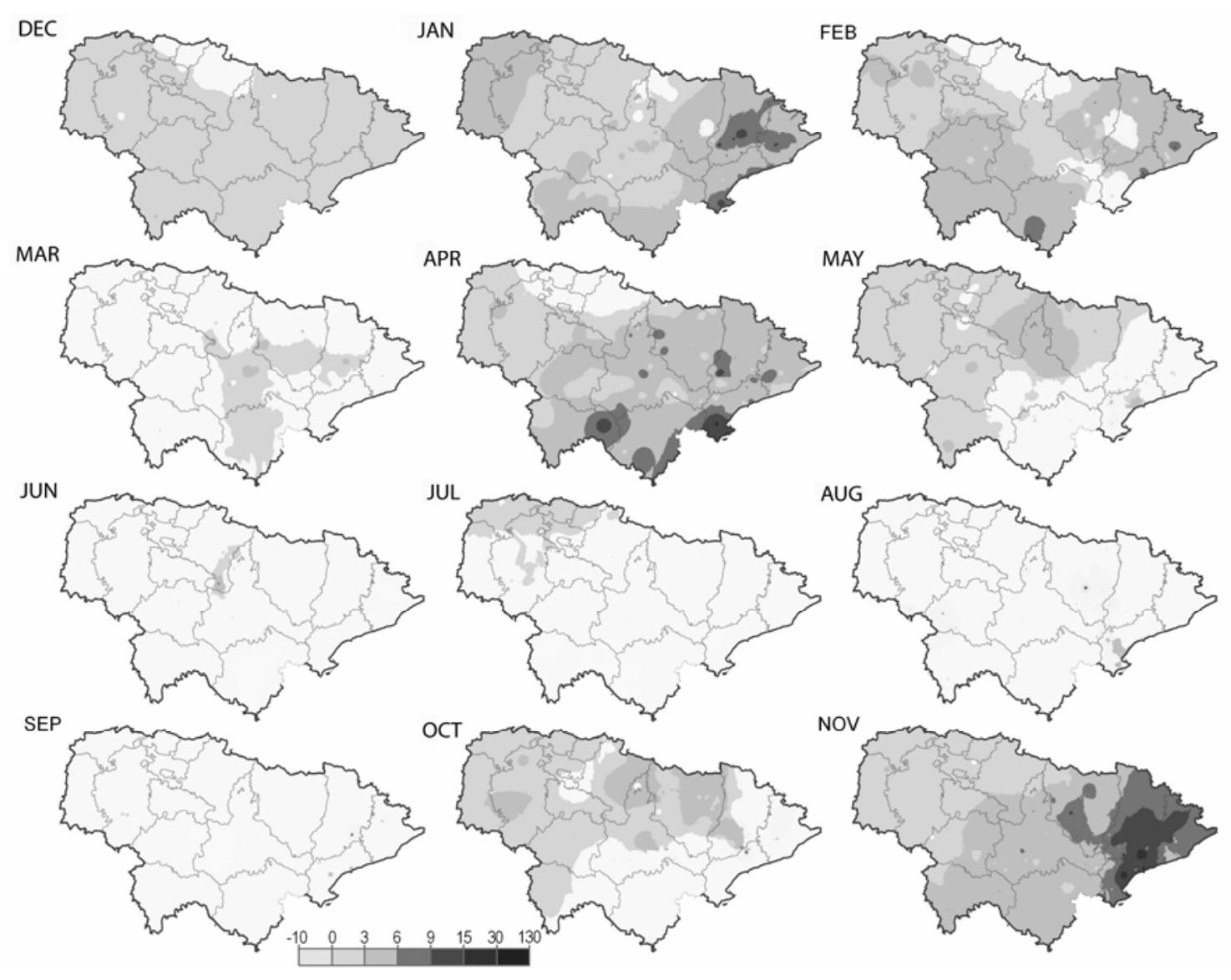


Figure 5

\section{L-moments plot}

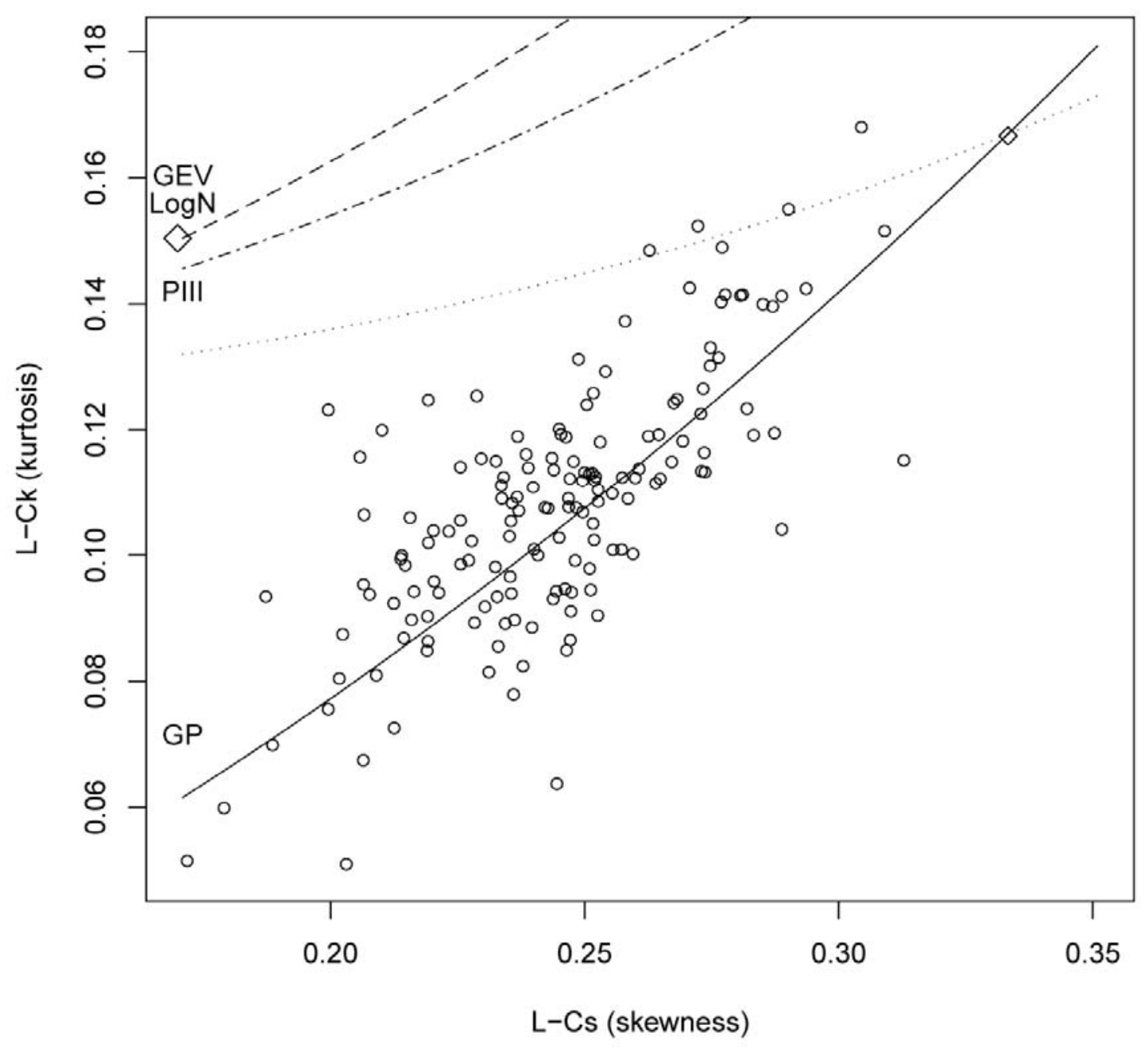


Figure 6
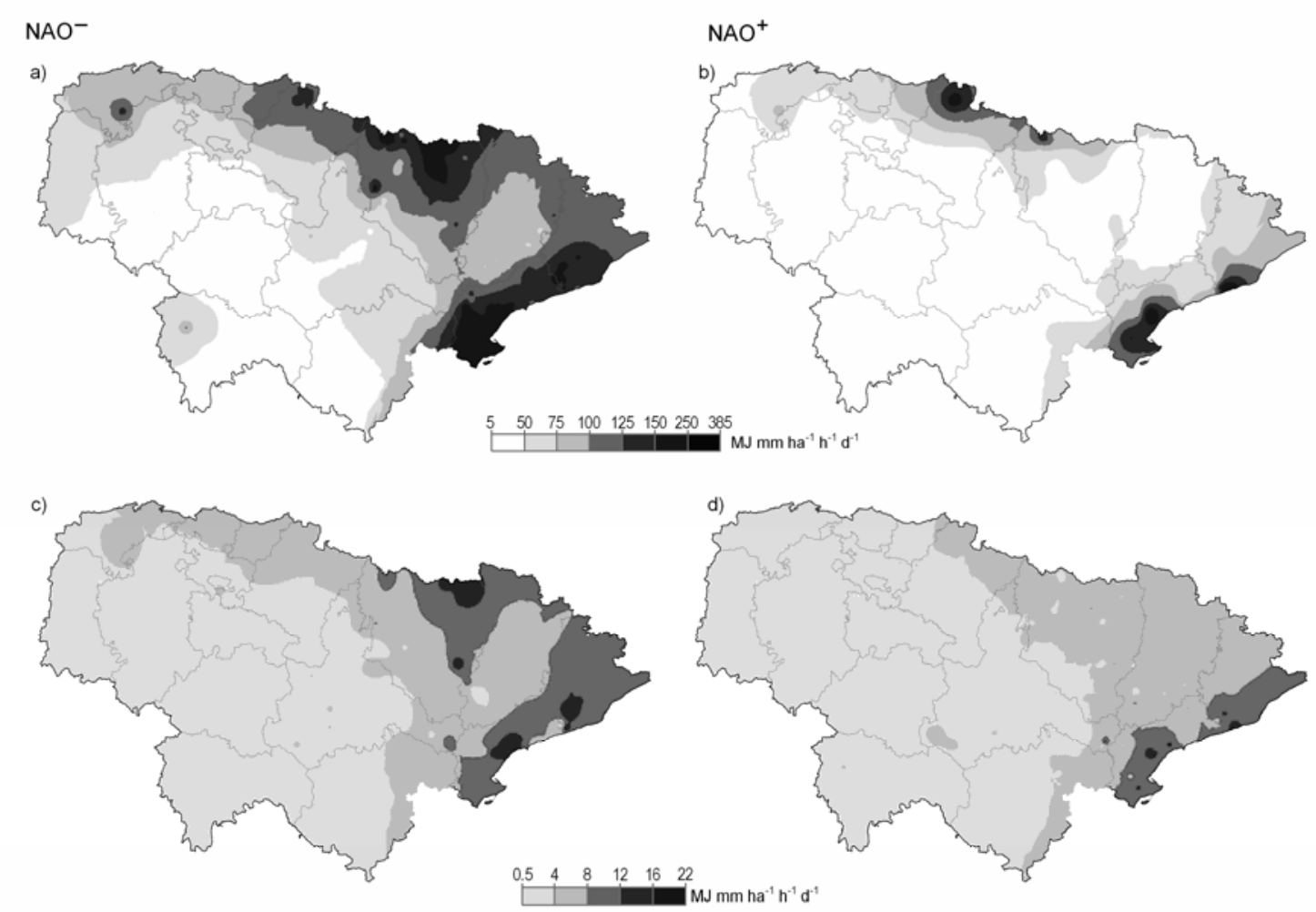


\section{Figure 7}

NAO

a)

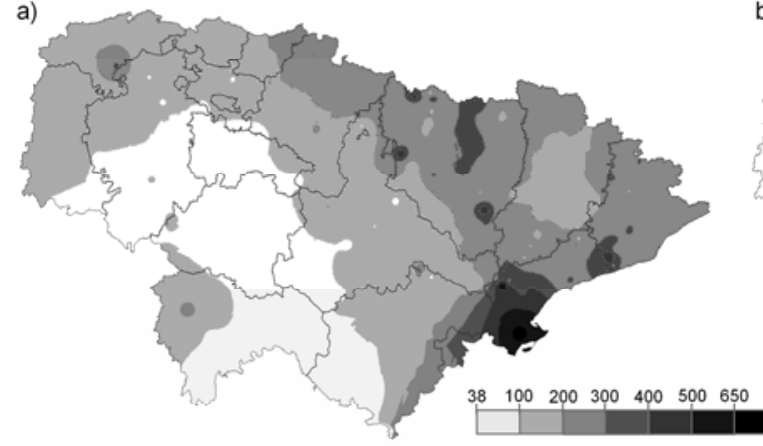

c)

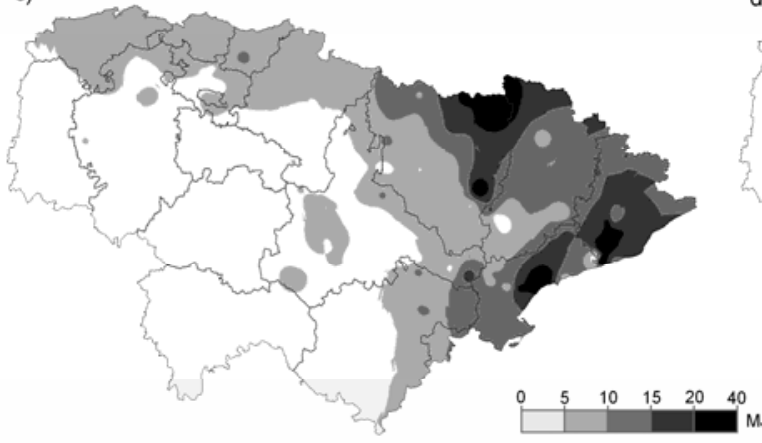

NAO

b)
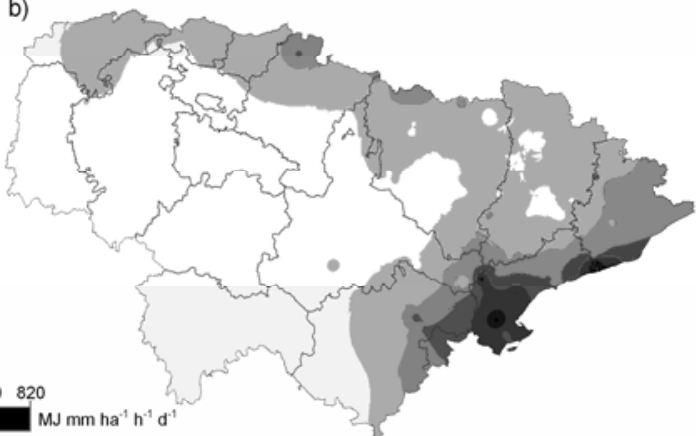

d)

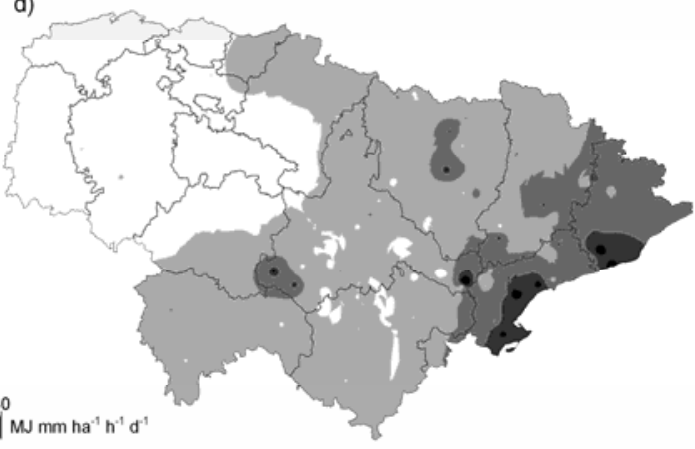

